Journal Club

Editor's Note: These short, critical reviews of recent papers in the Journal, written exclusively by graduate students or postdoctoral fellows, are intended to summarize the important findings of the paper and provide additional insight and commentary. For more information on the format and purpose of the Journal Club, please see http://www.jneurosci.org/misc/ifa_features.shtml.

\title{
Brain Age: A State-Of-Mind? On the Stability of Functional Connectivity across Behavioral States
}

\author{
기uien Dubois \\ Division of Humanities and Social Sciences, California Institute of Technology, Pasadena, California 91125 \\ Review of Geerligs et al.
}

The study of functional connectivity (FC) has become a major branch of functional MRI (fMRI) research. Biswal et al. (1995)'s seminal discovery, that voxels in the sensorimotor cortex exhibited highly correlated activity at rest, seeded the field; however, it took at least 10 more years for it to gain widespread interest (Cordes et al., 2000; Greicius et al., 2003; Fox et al., 2005; Smith et al., 2009). There is currently much research into using FC as a biomarker for clinical diagnosis (Greicius, 2008; Linden, 2012) and, more generally, to gain insight into individual differences in brain function (Smith et al., 2013). Most studies investigate FC in the socalled "resting state": subjects in the scanner are instructed to "lie still and think of nothing in particular," with eyes closed, or open and fixating (Patriat et al., 2013); however, FC can also be computed from task fMRI data, usually after regressing out stimulus-evoked activity (Fair et al., 2007).

Cole et al. (2014) showed that, on average across subjects, a reliable intrinsic network structure is preserved through all tasks and rest. Additionally, $\sim 40 \%$ of the connections show mild but significant changes that are task- (equivalently, state-) dependent. The variability of FC in individual subjects is now well recog-

Received Dec. 1, 2015; revised Jan. 6, 2016; accepted Jan. 11, 2016.

Correspondence should be addressed to Julien Dubois, California Institute of Technology, 1200 E. California Blvd., mc 114-96, Pasadena, CA 91125. E-mail: jcrdubois@gmail.com.

DOI:10.1523/JNEUROSCI.4312-15.2016

Copyright $\odot 2016$ the authors $\quad 0270-6474 / 16 / 362325-04 \$ 15.00 / 0$ nized; functional network structure actually moves through several states within the span of a single resting-state run (Hutchison et al., 2013; Allen et al., 2014). While some authors have used the dynamic nature of individual network structure to their advantage, e.g., Damaraju et al. (2014), there is growing concern that this variability could impede our ability to use FC as a stable, trait-like measure of individual subjects. A recent study in The Journal of Neuroscience (Geerligs et al., 2015) reinforces this concern.

Geerligs et al. (2015)'s study is among the first published outputs of the Cambridge Centre for Ageing and Neuroscience (Cam-CAN) cohort study, a large-scale $(N=\sim 700)$, multimodal (MRI, MEG, and behavioral), crosssectional, population-based adult lifespan (18-87 years old) investigation of the neural underpinnings of successful cognitive aging (Shafto et al., 2014; Taylor et al., 2015). Geerligs et al. (2015) used state-ofthe-art imaging and preprocessing techniques, notably with respect to motion correction, which has been a thorny issue in the functional connectivity literature (Power et al., 2012; Satterthwaite et al., 2012; Van Dijk et al., 2012; Tyszka et al., 2014), and is especially problematic in aging studies (older people tend to move more, as confirmed in this study). Geerligs et al. (2015)'s study boasts a final sample size of 587 subjects $(\sim 100$ per decade of life), all of whom completed three different tasks in the scanner: an $8 \mathrm{~min}$, $40 \mathrm{~s}$ eyes-closed resting-state run (REST state), an $8 \mathrm{~min}, 40 \mathrm{~s}$ sensorimotor task (detection of brief auditory tones and/or visual checkerboard flashes; TASK state), and an $8 \mathrm{~min}, 13 \mathrm{~s}$ movie-watching run (the movie being a shortened version of Alfred Hitchcock's television episode "Bang, you're dead!," as described in Hasson et al. (2010); MOVIE state).

Whole-brain FC was assessed among 748 nodes from a published functional parcellation (Craddock et al., 2012) (Fig. 1e), in each of the three states (REST, TASK, MOVIE), yielding a $748 \times 748$ FC matrix for each subject and each state (Fig. 1a). First, the authors performed the same analysis as Cole et al. (2014): they averaged FC matrices across subjects, then quantified the similarity of the average FC matrices for each pair of states using the Pearson correlation coefficient $r$ (Fig. 1b). As in Cole et al. (2014), they found a high similarity between the REST and TASK FC matrices [variance explained $r^{2}=$ $87 \%$ of total variance (TV)]. Crucially, Geerligs et al. (2015) also quantified the reliability of the average FC matrix in each state using a (conservative) splithalf procedure: the explainable variance (EV) was high (99\% TV), because of the large number of subjects. The variance attributable to state effects was thus $99 \% \mathrm{TV}-87 \% \mathrm{TV}=12 \% \mathrm{TV}$; i.e., $12 \% \mathrm{TV} / 99 \% \mathrm{TV}=11.9 \% \mathrm{EV}$, for the REST-TASK comparison.

The question that Geerligs et al. (2015) set out to answer is whether relationships between FC and age established in one 


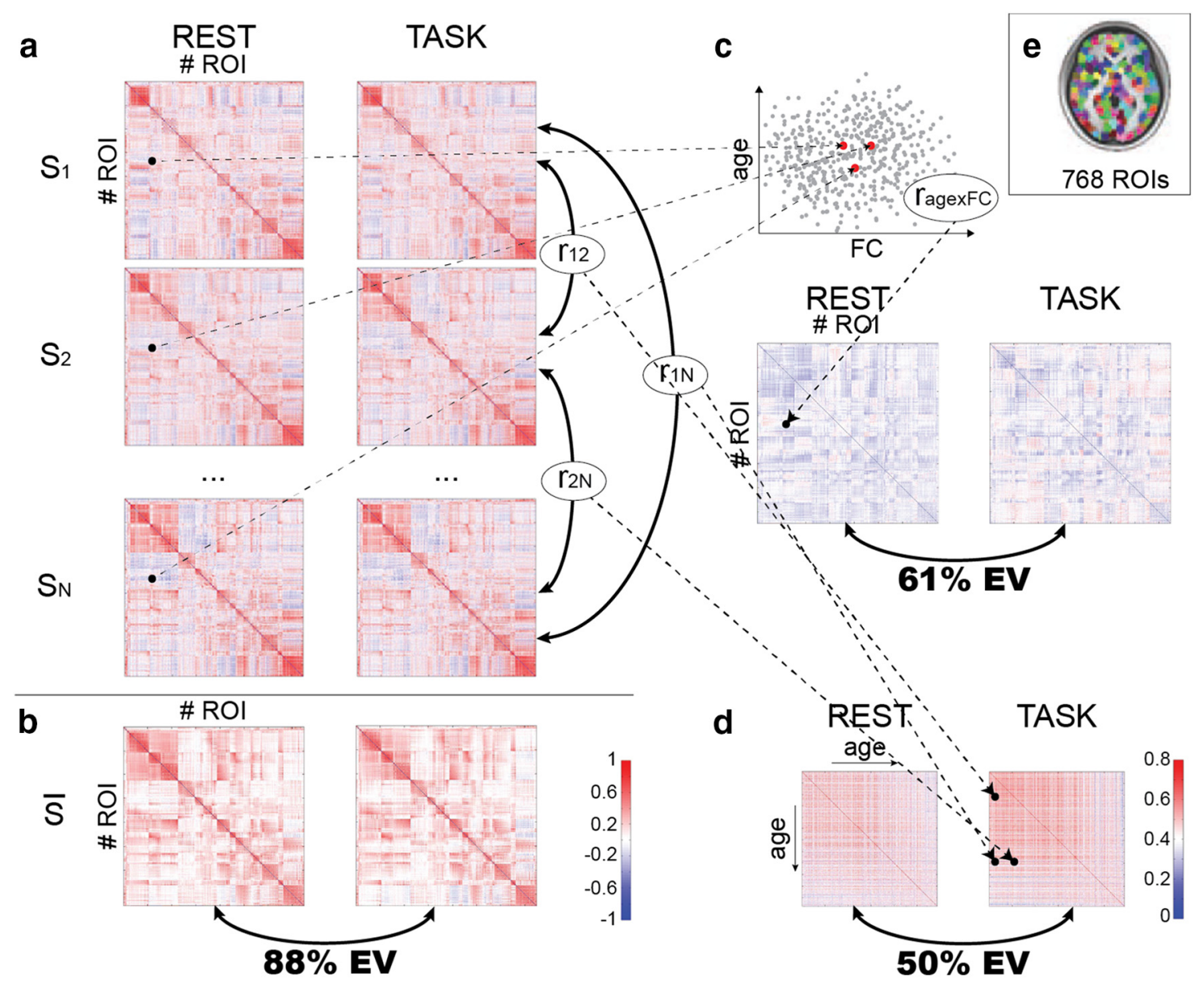

Figure 1. Geerligs et al. (2015)'s approach. $\boldsymbol{a}$, Functional connectivity is assessed between all pairs of Rols in the Craddock et al. (2012) parcellation, for each of the $N=587$ subjects $\left(S_{1}, S_{2}, \cdots\right.$ $S_{N}$ ) in each of three states (MOVIE not shown). $\boldsymbol{b}$, The average $\mathrm{FC}$ across subjects is calculated for each state; the matrices are compared across states using the Pearson correlation coefficient, from which the shared variance can be derived. c, For each edge, the correlation of the $\mathrm{FC}$ value with age is computed across subjects $\left(r_{\text {age }} \times \mathrm{Fc}\right)$; the resulting matrices for each state can then be compared and shared variance derived. $\boldsymbol{d}$, Subjects' $F($ matrices are compared using Pearson correlation, resulting is an $N \times N$ matrix of subject similarity for each state. The matrices are compared to establish shared variance. $\boldsymbol{e}$, The parcellation used for FC analyses; reproduced from Craddock et al. (2012), their Figure 3. (Matrices adapted from Geerligs et al. (2015), their Figs. 1-3; scatterplot in c for illustrative purposes only; color bar in $\boldsymbol{b}$ applies to $\boldsymbol{a}-\boldsymbol{c}$ ).

state still hold in a different state. Instead of looking at the average across subjects for each edge value (i.e., each value in the FC matrix), the authors computed the correlation of each edge value with age across subjects, again resulting in a $748 \times$ 748 matrix for each state (Fig. 1c). With the same matrix correlation approach as used previously, Geerligs et al. (2015) established that 53\% TV (61\%EV) was shared between REST and TASK runs, while $34 \% \mathrm{TV}(39 \% \mathrm{EV})$ was attributable to differences between these states. These results led Geerligs et al. (2015) to warn that the conclusions drawn regarding the effects of aging on FC would be "quite different" depending on the state that FC is measured in.

Finally, to make a more general point about individual differences inferred from FC, Geerligs et al. (2015) used the $748 \times 748$ FC matrix of each subject as a "fingerprint" (Miranda-Dominguez et al., 2014; cf. Finn et al., 2015) and computed the similarity between all pairs of subjects, resulting in a $587 \times 587$ subject similarity matrix for each of the three states (Fig. 1d). Again applying their matrix correlation approach, Geerligs et al. (2015) established that the similarities between subjects had approximately equal contributions from shared and state components (REST-TASK 50\%EV shared, $50 \% \mathrm{EV}$ state), thus replicating and extending the age-related result. A noteworthy result from this last analysis is that older subjects tended to have more idiosyncratic FC matrices (in all three states). Relatedly, Finn et al. (2015) recently showed, using fMRI data from the $\mathrm{Hu}$ man Connectome Project (HCP) (168 subjects), that the intrinsic component of the FC matrix of each subject allowed subject identification from FC matrices with very high accuracy across states (e.g., REST-TASK). In light of Geerligs et al. (2015)'s result, using older subjects (Finn et al. (2015)'s oldest subjects were 35 years old) may lead to even better identification accuracy.

In an additional set of analyses (the details of which are beyond the scope of this short commentary) Geerligs et al. (2015) looked at FC within and between 16 custom-defined functional networks, in an attempt to make more local claims on which within- and between-network connections are most affected by state, which are most related to age in each state, and finally, which connections show a significant interaction between state and their relationship to age.

Geerligs et al. (2015) conclude that FC should be assessed under a wide range of states for individual differences research, to disentangle state effects from more stable FC differences. This is certainly wise advice, although one could argue that traits need not be solely reflected in stable FC differences. For instance, if the aim is to uncover the brain correlates of individual differences in social cognition, the 
brain states of subjects watching a movie replete with social cues and interactions (Byrge et al., 2015) may be more informative than those of the same subjects listening to classical music.

Can we still use FC derived in one state (e.g., REST, the most often used, and often only available, kind of data) as a trait measure in the face of the reported state-related variability? Though Geerligs et al. (2015) write that "the regions exhibiting the strongest effects of aging on FC vary considerably between tasks," (p. 13959) the data are perhaps less alarming. The first set of analyses quantified variance of the entire FC matrix and thus included a lot of irrelevant information that potentially made the situation look much worse than it really is. The results presented by Geerligs et al. (2015) are in fact compatible with a situation in which a subset of the connections are trait-related and stable across states, while the rest of the connections are more state-dependent (and account for much of the state-related variance). It would have been informative to compute a metric such as the intraclass correlation coefficient (ICC) (Caceres et al., 2009) for each edge across states to identify the best candidates for trait-related connections, such as the ones that have a high ratio of intersubject variance (Mueller et al., 2013) to intrasubject variance (Laumann et al., 2015).

As a final note, establishing whether FC in a particular state can be used as a trait measure for age may have been better approached using a predictive framework. By building a (multivariate) predictive model for age from FC edges in, for example, the REST state (as in Dosenbach et al., 2010), and then testing whether the model generalizes to other states (TASK, MOVIE), one would find out whether the significant state-related variance reported by Geerligs et al. (2015) is of any practical importance. Better yet, by trying out different models (different feature selection mechanisms, different classifiers, etc.) in the REST data, and assessing how they generalize to other states, one may be able to formulate practical guidelines for building state-independent models from data collected in a single state. Luckily, given that this is a shared dataset (Taylor et al., 2015), the burden of conducting these additional analyses does not rest solely with the original authors; anybody interested in conducting them is able to do so.

\section{References}

Allen EA, Damaraju E, Plis SM, Erhardt EB, Eichele T, Calhoun VD (2014) Tracking whole-brain connectivity dynamics in the resting state. Cereb Cortex 24:630-676. CrossRef Medline

Biswal B, Yetkin FZ, Haughton VM, Hyde JS (1995) Functional connectivity in the motor cortex of resting human brain using echoplanar MRI. Magn Reson Med 34:537-541. CrossRef Medline

Byrge L, Dubois J, Tyszka JM, Adolphs R, Kennedy DP (2015) Idiosyncratic brain activation patterns are associated with poor social comprehension in autism. J Neurosci 35: 5837-5850. CrossRef Medline

Caceres A, Hall DL, Zelaya FO, Williams SC, Mehta MA (2009) Measuring fMRI reliability with the intra-class correlation coefficient. Neuroimage 45:758-768. CrossRef Medline

Cole MW, Bassett DS, Power JD, Braver TS, Petersen SE (2014) Intrinsic and task-evoked network architectures of the human brain. Neuron 83:238-251. CrossRef Medline

Cordes D, Haughton VM, Arfanakis K, Wendt GJ, Turski PA, Moritz CH, Quigley MA, Meyerand ME (2000) Mapping functionally related regions of brain with functional connectivity MR imaging. AJNR Am J Neuroradiol 21:1636-1644. Medline

Craddock RC, James GA, Holtzheimer PE 3rd, Hu XP, Mayberg HS (2012) A whole brain fMRI atlas generated via spatially constrained spectral clustering. Hum Brain Mapp 33:19141928. CrossRef Medline

Damaraju E, Allen EA, Belger A, Ford JM, McEwen S, Mathalon DH, Mueller BA, Pearlson GD, Potkin SG, Preda A, Turner JA, Vaidya JG, van Erp TG, Calhoun VD (2014) Dynamic functional connectivity analysis reveals transient states of dysconnectivity in schizophrenia. Neuroimage 5:298-308. CrossRef Medline

Dosenbach NU, Nardos B, Cohen AL, Fair DA, Power JD, Church JA, Nelson SM, Wig GS, Vogel AC, Lessov-Schlaggar CN, Barnes KA, Dubis JW, Feczko E, Coalson RS, Pruett JR Jr, Barch DM, Petersen SE, Schlaggar BL (2010) Prediction of individual brain maturity using fMRI. Science 329:1358-1361. CrossRef Medline

Fair DA, Schlaggar BL, Cohen AL, Miezin FM, Dosenbach NU, Wenger KK, Fox MD, Snyder AZ, Raichle ME, Petersen SE (2007) A method for using blocked and event-related fMRI data to study "resting state" functional connectivity. Neuroimage 35:396405. CrossRef Medline

Finn ES, Shen X, Scheinost D, Rosenberg MD, Huang J, Chun MM, Papademetris X, Constable RT (2015) Functional connectome fingerprinting: identifying individuals using patterns of brain connectivity. Nat Neurosci 18:1664-1671. CrossRef Medline

Fox MD, Snyder AZ, Vincent JL, Corbetta M, Van Essen DC, Raichle ME (2005) The human brain is intrinsically organized into dynamic, anticorrelated functional networks. Proc Natl Acad Sci U S A 102:9673-9678. CrossRef Medline

Geerligs L, Rubinov M, Cam-CAN, Henson RN (2015) State and trait components of func- tional connectivity: individual differences vary with mental state. J Neurosci 35 : 13949-13961. CrossRef Medline

Greicius M (2008) Resting-state functional connectivity in neuropsychiatric disorders. Curr Opin Neurol 21:424-430. CrossRef Medline

Greicius MD, Krasnow B, Reiss AL, Menon V (2003) Functional connectivity in the resting brain: A network analysis of the default mode hypothesis. Proc Natl Acad Sci U S A 100: 253-258. CrossRef Medline

Hasson U, Malach R, Heeger DJ (2010) Reliability of cortical activity during natural stimulation. Trends Cogn Sci 14:40-48. CrossRef Medline

Hutchison RM, Womelsdorf T, Allen EA, Bandettini PA, Calhoun VD, Corbetta M, Della Penna S, Duyn JH, Glover GH, GonzalezCastillo J, Handwerker DA, Keilholz S, Kiviniemi V, Leopold DA, de Pasquale F, Sporns O, Walter M, Chang C (2013) Dynamic functional connectivity: promise, issues, and interpretations. Neuroimage 80:360-378. CrossRef Medline

Laumann TO, Gordon EM, Adeyemo B, Snyder AZ, Joo SJ, Chen MY, Gilmore AW, McDermott KB, Nelson SM, Dosenbach NU, Schlaggar BL, Mumford JA, Poldrack RA, Petersen SE (2015) Functional system and areal organization of a highly sampled individual human brain article functional system and areal organization of a highly sampled individual human brain. Neuron 87:657-670. CrossRef Medline

Linden DE (2012) The challenges and promise of neuroimaging in psychiatry. Neuron 73: 8-22. CrossRef Medline

Miranda-Dominguez O, Mills BD, Carpenter SD, Grant KA, Kroenke CD, Nigg JT, Fair DA (2014) Connectotyping: model based fingerprinting of the functional connectome. PLoS One 9:e111048. CrossRef Medline

Mueller S, Wang D, Fox MD, Yeo BT, Sepulcre J, Sabuncu MR, Shafee R, Lu J, Liu H (2013) Individual variability in functional connectivity architecture of the human brain. Neuron 77:586-595. CrossRef Medline

Patriat R, Molloy EK, Meier TB, Kirk GR, Nair VA, Meyerand ME, Prabhakaran V, Birn RM (2013) The effect of resting condition on resting-state fMRI reliability and consistency: a comparison between resting with eyes open, closed, and fixated. Neuroimage 78:463-473. CrossRef Medline

Power JD, Barnes KA, Snyder AZ, Schlaggar BL, Petersen SE (2012) Spurious but systematic correlations in functional connectivity MRI networks arise from subject motion. Neuroimage 59:2142-2154. CrossRef Medline

Satterthwaite TD, Wolf DH, Loughead J, Ruparel K, Elliott MA, Hakonarson H, Gur RC, Gur RE (2012) Impact of in-scanner head motion on multiple measures of functional connectivity: Relevance for studies of neurodevelopment in youth. Neuroimage 60: 623-632. CrossRef Medline

Shafto MA, Tyler LK, Dixon M, Taylor JR, Rowe JB, Cusack R, Calder AJ, Marslen-Wilson WD, Duncan J, Dalgleish T, Henson RN, Brayne C, Matthews FE (2014) The Cambridge Centre for Ageing and Neuroscience (Cam-CAN) study protocol: a cross-sectional, lifespan, 
multidisciplinary examination of healthy cognitive ageing. BMC Neurol 14:204. CrossRef Medline

Smith SM, Fox PT, Miller KL, Glahn DC, Fox PM, Mackay CE, Filippini N, Watkins KE, Toro R, Laird AR, Beckmann CF (2009) Correspondence of the brain's functional architecture during activation and rest. Proc Natl Acad Sci U S A 106:13040-13045. CrossRef Medline

Smith SM, Beckmann CF, Andersson J, Auerbach EJ, Bijsterbosch J, Douaud G, Duff E, Feinberg
DA, Griffanti L, Harms MP, Kelly M, Laumann T, Miller KL, Moeller S, Petersen S, Power J, Salimi-Khorshidi G, Snyder AZ, Vu AT, Woolrich MW, et al. (2013) Restingstate fMRI in the Human Connectome Project. Neuroimage 80:144-168. CrossRef Medline

Taylor JR, Williams N, Cusack R, Auer T, Shafto MA, Dixon M, Henson RN (2015) The Cambridge Centre for Ageing and Neuroscience (Cam-CAN) data repository: structural and functional MRI, MEG, and cognitive data from a cross-sectional adult lifespan sample. Neuroimage. Advance online publication. CrossRef Medline

Tyszka JM, Kennedy DP, Paul LK, Adolphs R (2014) Largely typical patterns of restingstate functional connectivity in high-functioning adults with autism. Cereb Cortex 24:1894-1905. CrossRef Medline

Van Dijk KR, Sabuncu MR, Buckner RL (2012) The influence of head motion on intrinsic functional connectivity MRI. Neuroimage 59: 431-438. CrossRef Medline 